\title{
A BW Reporter System for Studying Receptor-Ligand Interactions
}

\author{
Shlomo Elias ${ }^{1,2}$, Shira Kahlon ${ }^{2}$, Alexandra Duev-Cohen ${ }^{2}$, Ofer Mandelboim ${ }^{2}$ \\ ${ }^{1}$ Department of Hematology, Hadassah - Hebrew University Medical Center ${ }^{2}$ The Lautenberg Center for General and Tumor Immunology, Department of \\ Immunology and Cancer Research, Institute for Medical Research Israel Canada (IMRIC), Hadassah - Hebrew University Medical Center
}

\section{Corresponding Authors}

Shlomo Elias

elias.shlomo@gmail.com

Ofer Mandelboim

oferm@ekmd.huji.ac.il

\section{Citation}

Elias, S., Kahlon, S., Duev-Cohen, A., Mandelboim, O. A BW Reporter System for Studying Receptor-Ligand Interactions. J. Vis. Exp. (143), e58685, doi:10.3791/58685 (2019).

\section{Date Published}

January 7, 2019

DOI

$10.3791 / 58685$

URL

jove.com/video/58685

\section{Abstract}

Interactions between receptors and ligands constitute a fundamental biological process. However, direct experiments with cells that express the native receptor and the ligand are challenging since the ligand of a specific receptor may be unknown and experimental procedures with the native ligand can be technically complicated. To address these obstacles, we describe a reporter system to detect the binding and activation of a specific receptor by a ligand of interest. In this reporter system, the extracellular domain of a specific receptor is conjugated to mouse $\operatorname{CD} 3 \zeta$ and this chimeric protein is then expressed in mouse BW cells. These transfected BW cells can then be incubated with different targets (e.g., cells or antibodies). Activation of a transfected receptor leads to the secretion of mouse interleukin-2 (mIL-2) which can be detected by enzyme-linked immunosorbent assay (ELISA). This reporter system has the advantages of being sensitive and specific to a single receptor. In addition, the activation level of a specific receptor can easily be quantified and can be used even in cases where the ligand of the receptor is unknown. This system has been implemented successfully in many of our studies to characterize receptor-ligand interactions. We have recently employed this system to study the activation of human Fcy receptors (FcyRs) by different monoclonal anti-CD20 antibodies in clinical use.

\section{Introduction}

The BW reporter system is a technique for studying receptorligand interactions ${ }^{1}$. This system is especially advantageous when the ligand of a specific receptor is unknown or experiments with the endogenous ligand are technically difficult. It can also be used for studying the binding of monoclonal antibodies to human FcyRs. The method is based on expressing a chimeric protein in mouse BW cells. This chimeric protein is composed of the extracellular domain of the receptor of interest fused to the transmembrane and intracellular domains of the mouse $\zeta$ chain. Binding of appropriate ligands of the receptor leads to secretion of mouse IL-2, which can be easily detected by ELISA, 
as illustrated in Figure 1. This method is sensitive and specific to an individual receptor, easy to operate, and highly reproducible. It can thus complement additional tools for studying receptor-ligand interactions. For example, it can be used to screen several cell lines for the presence of a ligand for a specific receptor (even if the ligand itself has not been identified) or to detect the activation of human FcyRs by monoclonal antibodies or by human serum containing anti-viral antibodies. Although primary immune cells express endogenous FcyRs, they are generally difficult to handle and usually express several Fc receptors.

We have used this system successfully in many of our studies to characterize receptor-ligand interactions. These include identifying haemagglutinin as the ligand of the NK cell receptor $\mathrm{NKp} 46^{2}$, identifying PVR and nectin-2 as ligands for human and mouse $\mathrm{TIGIT}^{3,4}$, and showing that the fusobacterium nucleatum bacterium binds and activates human $\mathrm{TIGIT}^{5}$. In addition, BW cells that express FC receptors have been used successfully to detect anti-viral antibodies in patients' sera $6,7,8$. Specifically, we recently established BW cells that express human FcyRs to detect differential FcR activation of anti-CD20 antibodies used for the treatment of chronic lymphocytic leukemia $(C L L)^{9}$. Importantly, the results of the BW reporter system have been validated in complementary experiments.

\section{Protocol}

\section{Generation of a Plasmid that Expresses the Chimeric Construct}

NOTE: The aim is to generate a plasmid that expresses the extracellular domain of the receptor of interest fused to the transmembrane and intracellular domains of the mouse $\mathrm{CD} 3 \zeta$ chain (Figure 2A).
1. Retrieve the sequence of the extracellular domain of the receptor of interest including the signal peptide. Obtain DNA material which is expected to express this receptor (e.g., cDNA or a plasmid).

2. Obtain DNA material that expresses the transmembrane and the intracellular domains of the mouse $C D 3 \zeta$ chain (e.g., cDNA or a plasmid).

3. Design the sequence of the fusion protein based on the general structure shown in Figure 2A. Make sure that the whole sequence is within the same codon reading frame. This sequence is used to design appropriate primers and verify the final product.

4. Design two PCR reactions to amplify each of the fragments of the fusion proteins separately (Figure 2B, 2C) ${ }^{10}$.

NOTE: The specific conditions for the PCR reactions (e.g., elongation time and annealing temperature) depend on the nature of the primers, which are designed for a specific receptor.

1. Amplify the extracellular segment of the receptor.

1. Design a $5^{\prime}$ primer that includes part of the signal peptide of the receptor, a Kozak consensus sequence, and an appropriate restriction site (Figure 2B).

2. Design a 3' primer that flanks both parts of the fusion protein (Figure 2B). For example, for the initial design this $3^{\prime}$ primer can include the last 20 base pairs of the extracellular segment of the receptor and the first 9 base pairs of $C D 3 \zeta$ segment.

NOTE: There is no need to add a restriction site to the $3^{\prime}$ primer since this primer will be used to 
generate the fused sequence, and is not used for ligation.

2. Amplify the $\mathrm{CD} 3 \zeta$ segment.

1. Design a 5' primer which flanks both parts of the fusion protein (Figure 2C). For example, for the initial design the $5^{\prime}$ primer can include the last 9 base pairs of the extracellular segment of the

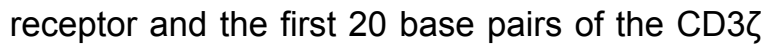
segment.

NOTE: There is no need to add a restriction site to the $5^{\prime}$ primer since this primer will be used to generate the fused sequence, and is not used for ligation.

2. Design a 3' primer which includes the end of the $\mathrm{CD} 3 \zeta$ sequence as well as an appropriate restriction site (Figure 2C).

3. Correct the primer sequences in each of these two reactions so that the annealing temperature is similar in each pair (note that the primer, which includes sequences of the two parts of the fusion protein, only anneals with part of the sequence in each reaction).

5. Perform an additional PCR in which a mixture of the PCR products of the first two reactions is used as the DNA template with the $5^{\prime}$ primer of the extracellular receptor segment (Step 1.4.1.1) and the $3^{\prime}$ of the CD3 segment (Step 1.4.2.2) (Figure 2D) ${ }^{10}$. This reaction should generate the final fused sequence.

6. Proceed as usual for cloning.

1. Ligate the final PCR product to the target cut vector (the target vector is usually pcDNA3 which expresses G418 and ampicillin resistance).
2. Transform the ligated vector into competent bacteria $^{11}$.

1. Thaw $50 \mu \mathrm{L}$ of the competent bacteria on ice.

2. Add the ligated vector to the bacteria and incubate on ice for $20 \mathrm{~min}$.

3. Incubate at $42^{\circ} \mathrm{C}$ for $45 \mathrm{~s}$.

4. Add $200 \mu \mathrm{L}$ of LB without antibiotics.

5. Incubate for $1 \mathrm{~h}$ at $37^{\circ} \mathrm{C}$ with continuous shaking.

6. Seed on an LB plate with the appropriate antibiotics (e.g., ampicillin solution with a final concentration of $0.1 \mathrm{mg} / \mathrm{mL}$ ).

3. Collect and grow several bacterial colonies in $5 \mathrm{~mL}$ of LB (in $15 \mathrm{~mL}$ tubes).

4. The next day, extract plasmids with a mini prep kit.

5. Analyze the gene insert with restriction enzymes.

6. Sequence the relevant colonies and verify that the sequence and the reading frame are correct (as indicated in Step 1.3).

7. Transform the verified plasmid into competent bacteria ${ }^{11}$.

1. Thaw $20 \mu \mathrm{L}$ of the competent bacteria on ice.

2. Add $1 \mu \mathrm{L}$ of the plasmid to the bacteria and incubate on ice for $20 \mathrm{~min}$.

3. Incubate at $42{ }^{\circ} \mathrm{C}$ for $45 \mathrm{~s}$.

4. Add $200 \mu \mathrm{L}$ of LB without antibiotics.

5. Incubate for $1 \mathrm{~h}$ at $37^{\circ} \mathrm{C}$ with continuous shaking.

6. Seed on a bacterial growth plate with the appropriate antibiotics (e.g., ampicillin solution with a final concentration of $0.1 \mathrm{mg} / \mathrm{mL}$ ). 
8. The next day, grow a bacterial colony in a large LB container with $0.1 \mathrm{mg} / \mathrm{mL}$ ampicillin $(\sim 250 \mathrm{~mL})$.

9. The next day, perform maxi prep according to the specific instructions provided by the kit.

NOTE: For the electroporation procedure, a large quantity of plasmid is required, as detailed below.

\section{Transfection of the Plasmid that Expresses the Chimeric Protein into BW Cells}

NOTE: Different methods can also be employed for transfection (e.g., by lentiviral infection). Prior to the electroporation, perform ethanol precipitation of the DNA as described below. The next steps require sterile conditions.

1. The day before, prepare the BW5147 cells ("BW cells") for electroporation. Plate 10 plates (of $10 \mathrm{~cm}$ ) with $10 \mathrm{~mL}$ of 100,000 BW5147 cells $/ \mathrm{mL}$ (i.e., a total of $10 \times 10^{6}$ cells) with RPMI supplemented with $10 \%$ fetal calf serum (FCS), $1 \%$ sodium pyruvate, $1 \%$ L-glutamine, $1 \%$ non-essential amino acids and 1\% penicillin-streptomycin ("complete medium").

2. Place $100 \mu \mathrm{g}$ of the pcDNA3 plasmid that expresses the fusion protein in a $1.5-2 \mathrm{~mL}$ tube and add $3 \mathrm{M}$ sodium acetate at $\mathrm{pH}$ 5.3-5.5 to it. The volume of the sodium acetate should correspond to $0.1(10 \%)$ of the volume of the $100 \mu \mathrm{g}$ plasmid; titrate the $\mathrm{pH}$ of the sodium acetate with a $\mathrm{pH}$ meter by adding $\mathrm{NaOH}$ or $\mathrm{HCl}$.

3. Add 2.5 volumes of $100 \%$ ethanol to the mixture of the plasmid and the sodium acetate as described in Step 2.2 (2.5x the total volume of plasmid and sodium acetate). Incubate overnight at $-20^{\circ} \mathrm{C}$ or for $2 \mathrm{~h}$ at $70^{\circ} \mathrm{C}$.

4. 2.4. $24 \mathrm{~h}$ after the BW cells have been plated, collect all the BW cells $(\sim 100 \mathrm{~mL})$ in $250 \mathrm{~mL}$ tubes. Centrifuge the cells for $5 \mathrm{~min}$ at $515 \times \mathrm{g}$ and discard the supernatant.
5. Re-suspend the pellet from both tubes in $25 \mathrm{~mL}$ of RPMIin a single $50 \mathrm{~mL}$ tube. For example, re-suspend the pellet of one tube with $25 \mathrm{~mL}$ of RPMI- and then use this fluid to re-suspend the fluid in the other $50 \mathrm{~mL}$ tube so that the total pellet from the BW cells is re-suspended in $25 \mathrm{~mL}$ of medium in a single tube.

NOTE: The medium should be without additions, since the serum might interfere with electroporation.

6. Centrifuge the cells again for $5 \mathrm{~min}$ at $515 \times \mathrm{g}$. Re-suspend the pellet in $1 \mathrm{~mL}$ of RPMI, and transfer the contents to a $0.4 \mathrm{~cm}$ cuvette on ice.

7. Centrifuge the plasmid that underwent ethanol precipitation (Step 2.3) for $30 \mathrm{~min}$ at $16,000 \times g$ and $4{ }^{\circ} \mathrm{C}$.

8. Wash once with $1 \mathrm{~mL}$ of $70 \%$ ethanol and centrifuge for another $20 \mathrm{~min}$ at $16,000 \times \mathrm{g}$ and $4{ }^{\circ} \mathrm{C}$ (to wash out the salt).

9. Remove all the ethanol and let the pellet dry slightly (i.e., in an open tube in the tissue culture hood). Re-suspend the pellet with $100 \mu \mathrm{L}$ of RPMI- previously heated to $60^{\circ} \mathrm{C}$.

10. Add the re-suspended plasmid (Step 2.8) to the cells in the cuvette and incubate for $5 \mathrm{~min}$ on ice.

11. Electroporate the cells at $0.23 \mathrm{kV}, 250$ capacitation. This should take $\sim 4 \mathrm{~ms}$.

12. Transfer the electroporated cells to a $50 \mathrm{~mL}$ tube, add 50 $\mathrm{mL}$ of complete medium and centrifuge for $5 \mathrm{~min}$ at 515 $\times g$.

13. Discard the supernatant and re-suspend the cells with 50 $\mathrm{mL}$ of complete medium.

14. Plate the electroporated cells in $24-$ well culture dishes (1 $\mathrm{mL}$ per well, for a total of $\sim 50$ wells) and incubate at 37 ${ }^{\circ} \mathrm{C}$ and $5 \% \mathrm{CO}_{2}$ for $48 \mathrm{~h}$. 
15. Select the transfected cells with antibiotics. After $48 \mathrm{~h}$ add $1 \mathrm{~mL}$ of complete medium supplemented with $10 \mathrm{mg} / \mathrm{mL}$ G418 to each well (at this stage the final volume in each well is $2 \mathrm{~mL}$ and the final concentration of G418 in each well is $5 \mathrm{mg} / \mathrm{mL}$ ).

NOTE: If the plasmid contains a different antibiotic resistance, determine the antibiotic concentration required to kill the untransfected BW cells prior to this step.

16. Every $48 \mathrm{~h}$, carefully discard $1 \mathrm{~mL}$ of the upper volume of each well without stirring the medium in the well (the BW cells tend to be at the bottom of the well). Add complete medium supplemented with $5 \mathrm{mg} / \mathrm{mL}$ G418 to each well, so that the final volume in each well is again $2 \mathrm{~mL}$.

17. Examine the culture plates for cell growth in all wells regularly.

NOTE: A change in the color of the medium to yellow may help identify growing cells; however, at the beginning the medium will be yellow because of the G418 itself. Identify positive wells (wells with growing cells). These wells are G418 resistant and therefore are expected to express the fusion protein. This process usually takes $\sim 3$ weeks.

\section{Verification of the Expression of the Transfected Receptor in Cells in the Positive Wells.}

1. Stain the transfected BW cells with a specific antibody against the receptor which was transfected.

2. Compare the expression level of the receptor by flow cytometry to the expression of the control cells (untransfected BW cells).

3. After verification of one or more wells, use cells immediately for experimental purposes, grow in culture, or freeze for future applications.
4. Verify the expression of the transfected receptor before performing a new experiment. After a few weeks of growth, the cells with G418 with a stable receptor expression, G418 can be omitted from the culture medium.

\section{Incubation of the Transfected BW Cells with Targets}

NOTE: When using the transfected BW cells for the first time, it is preferable to test them on targets that express a known ligand of the receptor of interest or on plate-bound antibodies specifically directed against the receptor of interest (crosslinking experiments; see below, section 4.2.1.3).

1. Preferably, split the BW cells $24 \mathrm{~h}$ before the experiment (for example, by adding $10 \mathrm{~mL}$ of complete medium to 2 $\mathrm{mL}$ of cells in culture in a new $10 \mathrm{~cm}$ culture plate).

2. Incubate the transfected BW cells with their targets. Perform the experiment simultaneously on control BW cells that express an empty vector (or parental BW cells). 96F plates are preferable (but $96 \mathrm{U}$ plates can also be used). Perform the experiment in triplicate. Suspend all the cells in the complete medium.

1. Prepare the targets. The type of target varies as a function of the objective, and can be cells, cells that have been pre-incubated with antibodies, or antibodies alone. This system has also been used with bacteria as targets ${ }^{5}$.

1. If the targets are dividing cells (i.e., cell lines), irradiate them at 6,000 rad prior to the assay. Place 50,000 of the target cells in a single well of a 96 plate (in a volume of $100 \mu \mathrm{L}$ ).

2. For experiments with antibodies and BW cells that express human FcyRs, incubate the target cells 
with an antibody on ice in a 96 well plate (for example, $50 \mu \mathrm{L}$ of the target cells and $50 \mu \mathrm{L}$ of the antibody; different antibody doses can be tested).

3. If using antibodies alone as targets (cross-linking experiments), they should be plate- bound. For this purpose, first incubate the antibodies in a complete medium in a $96 \mathrm{~F}$ plate for $1-2 \mathrm{~h}$ at 37 ${ }^{\circ} \mathrm{C}$ and $5 \% \mathrm{CO}_{2}$ (a typical starting dose is $0.5 \mu \mathrm{g}$ of a specific antibody in $50 \mu \mathrm{L}$ ). Wash the plate to remove unbound antibodies.

NOTE: In this case, a 96F plate will enable binding of the antibody to the plate, which after addition of the transfected BW cells will lead to activation of the transfected receptor.

2. Add the BW cells (effector cells). Place 50,000 BW cells in a single well of a 96 plate (in a volume of 100 $\mu L)$.

3. Complete the volume in each well to $200 \mu \mathrm{L}$ if necessary.

4. Incubate the plates at $37^{\circ} \mathrm{C}$ and $5 \% \mathrm{CO}_{2}$ for $48 \mathrm{~h}$ (this time period can be calibrated).

3. After $48 \mathrm{~h}$, freeze the plates at $-20^{\circ} \mathrm{C}$ and thaw prior to ELISA, or use immediately for ELISA (see next steps).

\section{ELISA}

1. Coat an ELISA plate with an anti-mouse IL-2 antibody (anti-mIL-2). Place $0.05 \mu \mathrm{g}$ of anti-mlL-2 in a volume of 50 $\mu \mathrm{L}$ of $1 \mathrm{x}$ PBS per well. Incubate the coated ELISA plate with the anti-mIL-2 antibody at $4{ }^{\circ} \mathrm{C}$ overnight or at $37^{\circ} \mathrm{C}$ for $2 \mathrm{~h}$.

NOTE: To perform ELISA directly after the incubation step, the ELISA plate should be coated $24 \mathrm{~h}$ before the end of the incubation period of the BW cells.
2. Discard the fluid in the ELISA plate and add a blocking solution (200 $\mu \mathrm{L}$ per well) which is composed of $1 \times$ PBS and $1 \%$ bovine serum albumin (BSA). Incubate the ELISA plate for $2 \mathrm{~h}$ at room temperature.

3. Wash the ELISA plate three times with $0.05 \%$ PBS Tween solution (i.e., $0.5 \mathrm{~mL}$ of Tween-20 in 1 liter of 1x PBS).

4. Take the 96 plate which has the BW cells that were incubated with their targets (4.3). If the plate was frozen, completely thaw it (e.g., by short incubation at $37^{\circ} \mathrm{C}$ ). Centrifuge the 96 plate $(5 \mathrm{~min}, 515 \times \mathrm{g})$ and carefully transfer $100 \mu \mathrm{L}$ of the supernatant in each well to the precoated and blocked ELISA plate.

NOTE: The supernatant should be collected from the sides of each well to avoid taking the cells.

5. If desired, add recombinant mIL-2 with defined concentrations to one of the empty rows of the coated ELISA plate to generate a standard curve of mIL-2. For example, start from a mlL-2 concentration of $2,500 \mathrm{pg} / \mathrm{mL}$ and then decrease by $50 \%$ in each subsequent well; do not add $\mathrm{mIL}-2$ to the last well.

6. Incubate the ELISA plate at $4{ }^{\circ} \mathrm{C}$ overnight or at $37^{\circ} \mathrm{C}$ for $2 \mathrm{~h}$.

7. Wash the ELISA plate four times with PBS Tween.

8. Add biotin anti-mouse IL-2 to the ELISA plate. Use a concentration of $1 \mu \mathrm{g}$ antibody in $1 \mathrm{~mL}$ of $1 \mathrm{x}$ PBS with $1 \%$ BSA and divide into $100 \mu \mathrm{L}$ per well.

9. Incubate at room temperature for $1 \mathrm{~h}$.

10. Wash the ELISA plate six times with PBS Tween.

11. Add HRP conjugated streptavidin. Use a concentration of $1 \mu \mathrm{L}$ streptavidin in $1 \mathrm{~mL}$ of PBSX1 with $1 \% \mathrm{BSA}$ and divide it into $100 \mu \mathrm{L}$ per well.

12. Incubate at room temperature for $30 \mathrm{~min}$. 
13. Wash the ELISA plate six times with PBS Tween.

14. Add $100 \mu \mathrm{L}$ per well of TMB substrate solution. Complete this stage quickly to minimize differences between the wells due to time lags when adding the TMB.

15. Read the ELISA plate with an ELISA plate reader at 650 $\mathrm{nm}$ (the reading can be repeated if the signal is weak).

\section{Representative Results}

Figure 3 illustrates the results of an experiment with a BW reporter system. In this experiment, CLL cells were preincubated with different anti-CD20 antibodies (rituximab and obinutuzumab) and then co-incubated with transfected BW cells which express CD16a-CD3ろ. Similar experiments were conducted in our study ${ }^{9}$. Figure $3 A$ presents an image of a raw ELISA plate where the color intensity corresponds to a concentration of $\mathrm{mlL}-2$. The experiment was performed in triplicate. This experiment included several controls: CLL cells incubated with parental untransfected BW cells (upper row) and CLL cells incubated with BW cells which express CD16a-
CD3 $\zeta$ but without an antibody or with a control antibody (six wells in the second row on the left). The incubation of BW cells that expressed CD16 with CLL cells that were preincubated with anti-CD20 antibodies induced a significant secretion of mIL-2 compared to the mIL-2 level of the control wells. Importantly, pre-incubation of the CLL cells with the anti-CD20 obinutuzumab activated CD16 more strongly than rituximab, a known finding which was recapitulated by our system. The last row shows descending pre-defined concentrations of recombinant mIL-2 (without the addition of cells). The right well in the last row does not have mIL-2 and represents the background reading, which appears similar to the control wells. Figure 3B presents the quantification of the results of the ELISA plate shown in Figure 3A. The optical density (OD) levels were converted into $\mathrm{mIL}-2$ concentrations based on the standard curve with recombinant mlL-2. Figure 3C presents a dose response experiment where different doses of antibodies were pre-incubated with CLL cells and then incubated with BW cells expressing CD16.

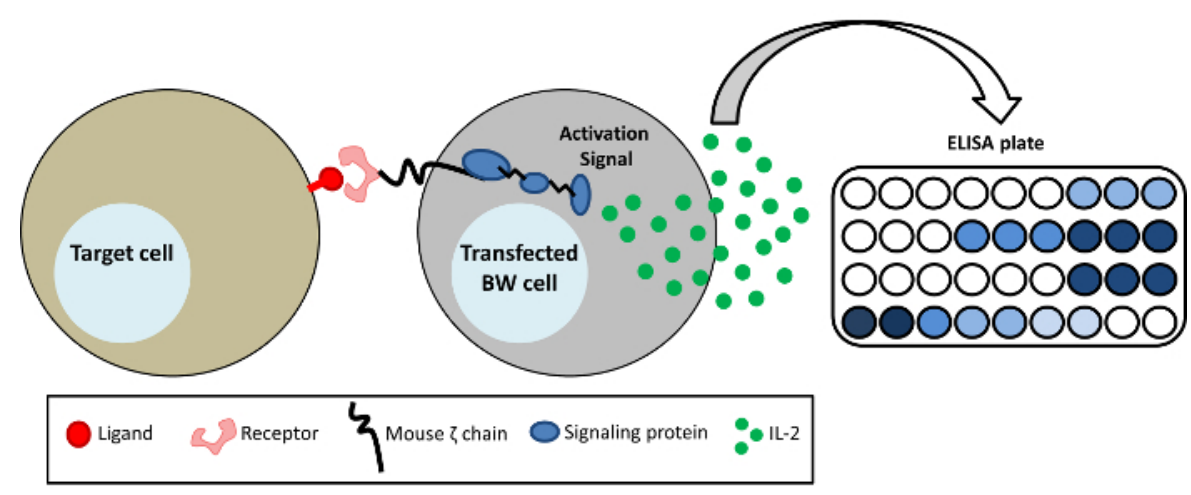

Figure 1: Schematic representation of the BW reporter system. BW5147 cells are stably transfected with the extracellular portion of different receptors fused to the transmembrane and cytoplasmic domains of the mouse CD3 $\zeta$ chain

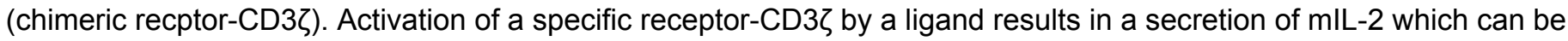
detected by ELISA. Please click here to view a larger version of this figure. 


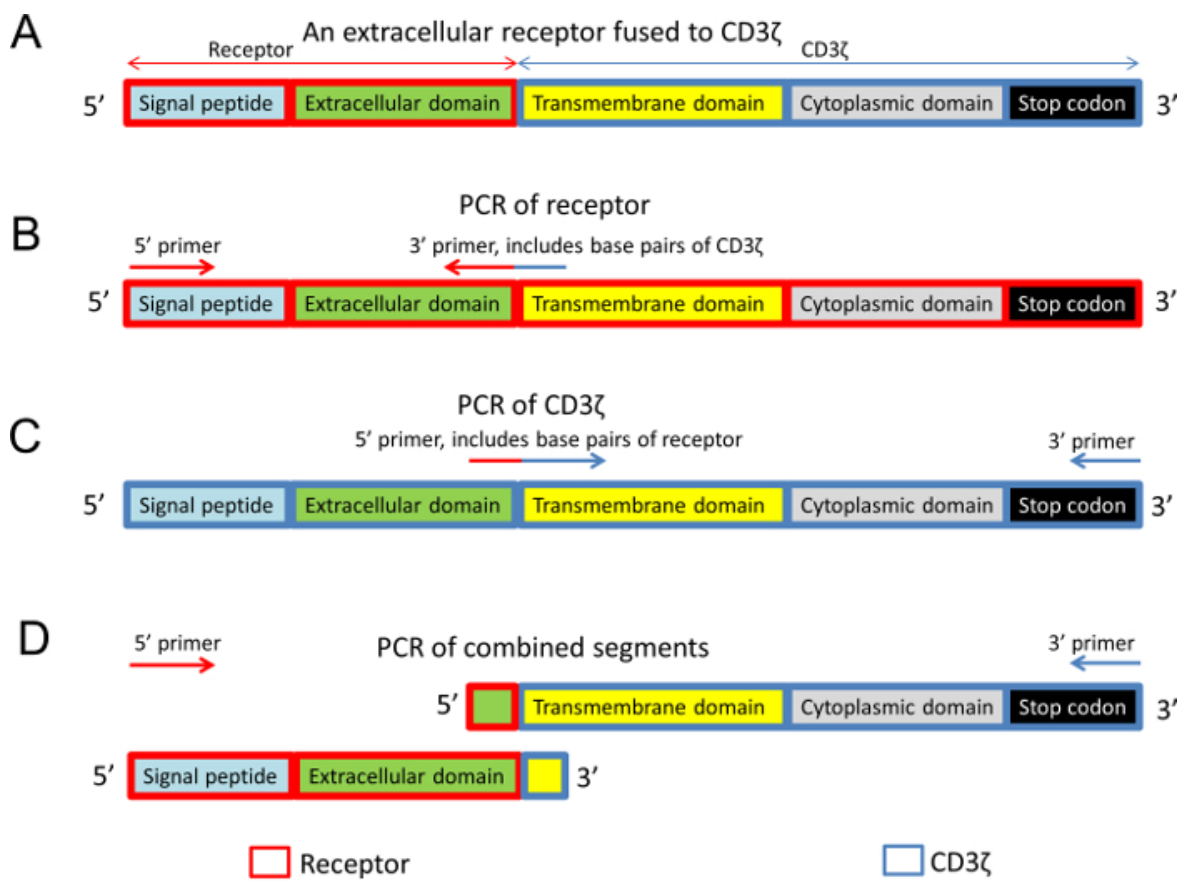

Figure 2: The structure of the chimeric receptor-CD3ろ and the design of PCR primers. (A) General structure of an extracellular receptor fused to the transmembrane and intracellular domains of mouse CD3ろ. (B) The extracellular domain of the receptor was amplified with a 3' primer which also included nucleotides of CD3ろ. (C) The intracellular and transmembrane domains of $\mathrm{CD} 3 \zeta$ were amplified with a 5' primer that also included receptor nucleotides. (D) In the final PCR reaction, both segments, which have overlapping sequences, were used as the DNA template. In all figure panels, different protein domains are color-coded and boxed in blue rectangles (CD3 $\zeta$ sequence) and red rectangles (the receptor sequence). Please click here to view a larger version of this figure. 

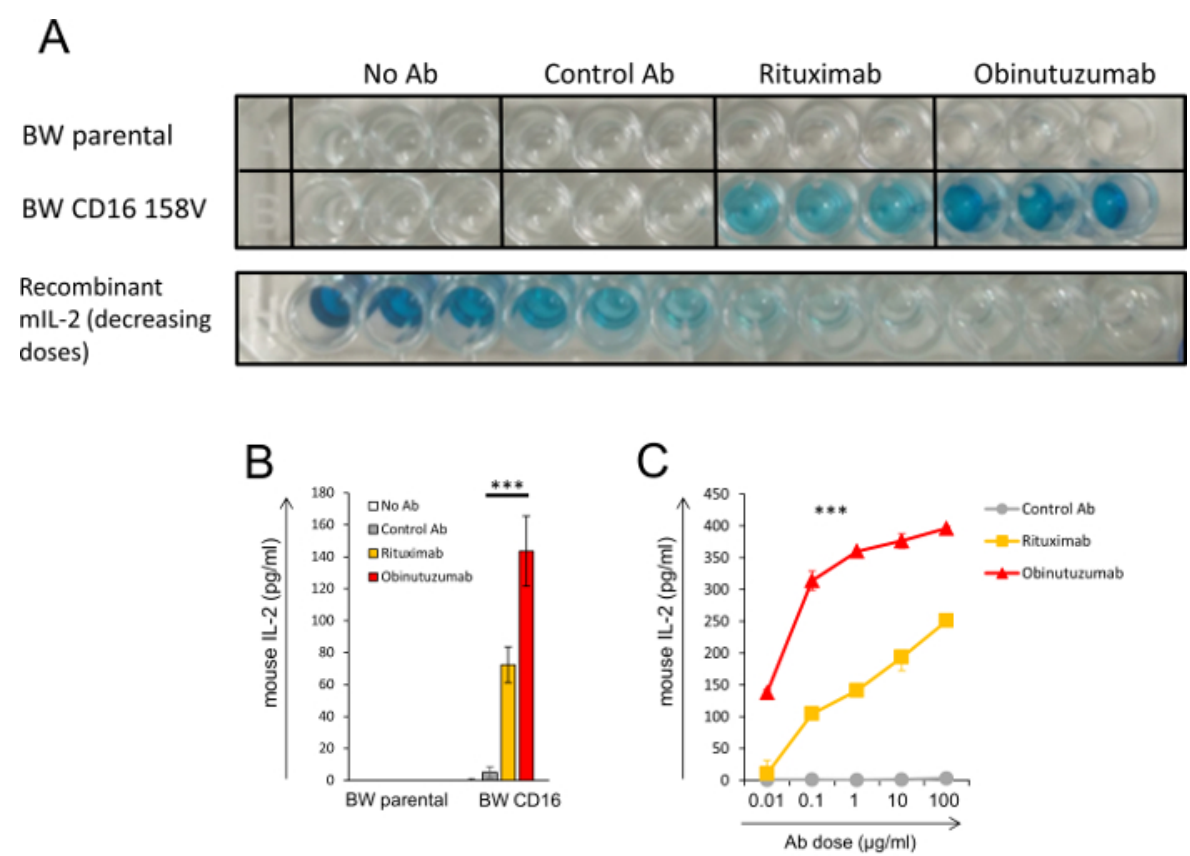

Figure 3: Illustration of the final product of the BW reporter system. (A, B, C) CLL cells were pre-incubated with or without two anti-CD20 antibodies (rituximab and obinutuzumab) or a control antibody. Afterwards, the antibody-bound cells were incubated with parental BW cells or BW cells which express CD16a-CD3ろ. The level of mIL-2 in the supernatant was determined by ELISA. (A) An image of a raw ELISA plate. Color intensity indicates the concentration of mIL-2 in the supernatant. The experiment was performed in triplicate. The lower row shows the ELISA readout in decreasing concentrations of recombinant mIL-2 which were analyzed in the same plate. (B) Quantification of the ELISA reading shown in (A). The mIL-2 levels were calculated using a standard curve of mil-2. (C) A dose response experiment where different

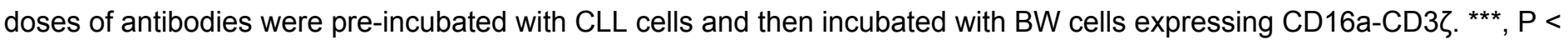
0.001; Student's $t$ test (B) or ANOVA with multiple comparisons (C). The only comparison in (C) which was not significantly different was for rituximab and the control $A b$ in the first concentration $(0.01 \mu \mathrm{g} / \mathrm{mL})$. Error bars represent the standard deviation of the triplicates. Similar experiments were conducted as part of one of our recent study ${ }^{9}$. Please click here to view a larger version of this figure.

\section{Discussion}

Here we present a protocol for generating a reporter system to investigate receptor-ligand interactions (see an abbreviated form of this protocol in ${ }^{1}$ ). The protocol is composed of three main parts: cloning of a chimeric protein, which includes the extracellular domain of a specific receptor fused to the intracellular domain of $\mathrm{CD} 3 \zeta$, transfection of a plasmid that expresses the fusion protein to BW cells (e.g., by electroporation), and quantitative detection of mouse IL-2 by ELISA. The final product of each of these parts should be verified independently: the cloning process should be verified by complete sequencing of the fusion protein in the target 
plasmid, the transfection of the BW cells should be verified by examining the expression of the receptor of interest in the BW cells (e.g., by flow cytometry), and the ELISA process should be verified by general positive controls (e.g., recombinant mIL-2) as well as with specific controls for the transfected BW cells; i.e., targets that express a known ligand of the receptor of interest (e.g., cells that express CD48 can be used as a positive control for BW cells that express the NK cell receptor 2B4). For instance, the cloning process may be successful, but the fusion protein is not expressed by the BW cells. In this case, the electroporation should be repeated. Alternatively, if there is no signal above the background level of the ELISA plate (especially for the positive controls) the transfected BW cells may have failed to express the receptor (or the expression has been lost) or a technical problem may have occurred during the ELISA process.

Several modifications can be made to this protocol while preserving the general principles of the procedure. These modifications include the vector used to express the fusion protein, the method for transfecting the plasmid to BW cells and specific parameters related to the incubation and ELISA such as the type of target (e.g., cells, antibodies, etc.), number of target cells or the antibody concentration if relevant (we use 50,000 cells per well and an antibody starting dose of 0.5 $\mu \mathrm{g} /$ well), incubation time (we use an incubation time of $48 \mathrm{~h}$ ) and the supernatant volume which is transferred to the ELISA plate.

This method is sensitive, specific and can be easily quantified. It is ideal for screening for the presence of ligands for specific receptors (especially if the ligand itself has not been recognized). After preparing transfected BW cells that express a specific receptor, these cells can be frozen and used when needed for additional experiments.
We and others have used this system successfully in previous studies to explore receptor-ligand interactions (for example $\left.^{2}, 3,5,12,13,14,15,16\right)$ and the results obtained by this system have been verified by other techniques. This method can also be used to study the activation of different human FcyR receptors by antibodies, as has been done for anti-viral antibodies in serum ${ }^{6,7,8}$ or with monoclonal antibodies against $\mathrm{CD} 20^{9}$.

Since this is a reporter system in which only the extracellular segment of the receptor is expressed, the findings obtained by this system should be complemented by additional experiments with the endogenous receptor, such as cytotoxicity assays with natural killer (NK) cells to study interactions with NK cell receptors. Moreover, certain ligand/ receptor interactions may not result in a mIL-2 secretion by the reporter system, and therefore might be overlooked. In addition, as in any experimental setup, the results should be verified for various parameters as described above. This is especially important in cases where a comparison of two conditions is required (e.g., activation of the same Fc receptor by different antibodies). It is also important to verify that the sensitivity of a specific ligand-receptor interaction is within the linear range of the system. Otherwise this could lead to saturation values which may preclude a valid comparison across conditions. This can be achieved by using a mlL-2 standard curve as well as by generating a dose-response curve with the tested ligand (in the case of saturating values, the experimental parameters should be modified; e.g., a smaller volume of supernatant should be analyzed by ELISA). Another possible limitation of this system is the use of target cells with endogenous secretions of mIL-2 (e.g., mouse T cells) which would mask the IL-2 secretion of BW cells. To overcome these highly unusual occurrences which are confined to mouse cells, this reporter system could 
be improved by using a different reporter (e.g., GFP) which is not expressed by the target cells.

\section{Disclosures}

The authors declare no competing financial interests.

\section{Acknowledgments}

The authors thank Esther Singer for language editing. This study was supported by the European Research Council under the European Union's Seventh Framework Programme (FP/2007-2013) / ERC Grant Agreement number 320473BacNK. Further support was provided by the I-CORE Program of the Planning and Budgeting Committee and the Israel Science Foundation and by the I-Core on Chromatin and RNA in Gene Regulation, the GIF Foundation, the Lewis Family Foundation, the ICRF professorship grant, the Helmholtz Israel grant and the Rosetrees Trust (all to O.M.). This study was also supported by the Israel Science Foundation (grant 502/15), the Kass Medical Research Award and a research grant from the Israel Society of Hematology and Transfusion Medicine (to S.E). O.M is a Crown professor of Molecular Immunology.

\section{References}

1. Mandelboim, O., Lankry, D., Gazit, R. Natural Killer Cell Protocols. Second edn, 258-262 Humana Press (2010).

2. Mandelboim, O. et al. Recognition of haemagglutinins on virus-infected cells by NKp46 activates lysis by human NK cells. Nature. 409 (6823), 1055-1060 (2001).

3. Stanietsky, N. et al. The interaction of TIGIT with PVR and PVRL2 inhibits human NK cell cytotoxicity. Proceedings of the National Academy of Sciences of the United States of America. 106 (42), 17858-17863 (2009).
4. Stanietsky, N. et al. Mouse TIGIT inhibits NK-cell cytotoxicity upon interaction with PVR. European Journal of Immunology. (2013).

5. Gur, C. et al. Binding of the Fap2 protein of Fusobacterium nucleatum to human inhibitory receptor TIGIT protects tumors from immune cell attack. Immunity. 42 (2), 344-355 (2015).

6. Corrales-Aguilar, E. et al. A novel assay for detecting virus-specific antibodies triggering activation of Fcgamma receptors. Journal of Immunoogical Methods. 387 (1-2), 21-35 (2013).

7. Corrales-Aguilar, E. et al. Highly individual patterns of virus-immune IgG effector responses in humans. Medical Microbiology and Immunology. 205 (5), 409-424 (2016).

8. Radinsky, O. et al. Sudan ebolavirus long recovered survivors produce GP-specific Abs that are of the $\lg \mathrm{G} 1$ subclass and preferentially bind FcgammaRI. Scientific Reports. 7 (1), 6054 (2017).

9. Elias, S., Kahlon, S., Kotzur, R., Kaynan, N., \& Mandelboim, O. Obinutuzumab activates FcgammaRI more potently than other anti-CD20 antibodies in chronic lymphocytic leukemia (CLL). Oncoimmunology. 7 (6), e1428158 (2018).

10. Lorenz, T. C. Polymerase chain reaction: basic protocol plus troubleshooting and optimization strategies. Journal of Visualized Experiments. (63), e3998 (2012).

11. Froger, A., \& Hall, J. E. Transformation of plasmid DNA into E. coli using the heat shock method. Journal of Visualized Experiments. (6), 253 (2007).

12. Bar-On, Y. et al. NKp46 Recognizes the Sigma1 Protein of Reovirus: Implications for Reovirus-Based Cancer Therapy. Journal of Virology. 91 (19) (2017). 
13. Glasner, A. et al. Expression, Function, and Molecular Properties of the Killer Receptor Ncr1-Noe. Journal of Immunology. 195 (8), 3959-3969 (2015).

14. Glatzer, T. et al. RORgammat(+) innate lymphoid cells acquire a proinflammatory program upon engagement of the activating receptor NKp44. Immunity. 38 (6), 1223-1235 (2013).

15. Gur, C. et al. The activating receptor NKp46 is essential for the development of type 1 diabetes. Nature Immunology. 11 (2), 121-128 (2010).

16. Markel, G. et al. Pivotal role of CEACAM1 protein in the inhibition of activated decidual lymphocyte functions. Journal of Clinical Investigation. 110 (7), 943-953 (2002). 